\title{
Abdominal Wall Endometriosis: Purpose of a Case and Review of Literature
}

\author{
Sonia Oliva ${ }^{1}$, Daniel Correa López ${ }^{2, *}$, Brayan Molano ${ }^{3}$ \\ ${ }^{1}$ Gynecology and Obstetrics Service, Departmental University Hospital, Nariño, Colombia \\ ${ }^{2}$ Program of Medicine, Faculty of Health Sciences Pontifical Javeriana University, Cali, Colombia \\ ${ }^{3}$ Program of Medicine, Faculty of Health Sciences Cooperative University of Colombia, Pasto, Colombia
}

Email address:

soniaandreaolivam@hotmail.com (S. Oliva),danielc_079@hotmail.com (D. C. López)

${ }^{*}$ Corresponding author

\section{To cite this article:}

Sonia Oliva, Daniel Correa López, Brayan Molano. Abdominal Wall Endometriosis: Purpose of a Case and Review of Literature. Journal of Gynecology and Obstetrics. Vol. 8, No. 6, 2020, pp. 186-190. doi: 10.11648/j.jgo.20200806.16

Received: October 6, 2020; Accepted: October 29, 2020; Published: November 16, 2020

\begin{abstract}
Endometriosis of the abdominal wall is defined as the presence of superficial ectopic endometrial tissue to the parietal peritoneum, whose origin may be associated with previous gynecological surgical procedures. Its prevalence is low, around $0.03 \%$, being the first isolated case in our institution, its report and bibliographic review was necessary. The following paper is a case report and a brief bibliographic literature review. Endometriosis is defined as the presence of endometrial glands and stroma outside the uterine cavity. The definition includes injuries that may or may not be related to previous surgical procedures. It is associated with cesarean section in $57 \%$ and hysterectomy in $17 \%$. We present the case of a 37 years old female patient, with a history of three previous cesarean sections 3, 6 and 10 years ago; who presented a clinical picture of a sensation of a mass in the abdominal wall, accompanied by cyclical pain and mass growth related to menstrual periods. Abdominal ultrasound reported a heterogeneous vascularized $4 \times 5 \mathrm{~cm}$ mass. She underwent surgery at our institution where an endometrial mass was evidenced that infiltrated the rectus abdominis, later the diagnosis was confirmed with the histopathological study. Abdominal endometriosis is a rare entity in medical practice. A high index of suspicion should be considered in the case of a woman who presents with disabling abdominal pain located in the abdominal wall, with a history of previous gynecological surgical procedures. This pathology can be confused with many other surgical entities; for this reason, resorting to paraclinical studies can be essential in the diagnostic certainty.
\end{abstract}

Keywords: Endometriosis, Abdominal Wall, Endometrioma, Case Report

\section{Introduction}

Endometriosis is classically defined as the presence of endometrial cell glands and stroma outside the uterine cavity [1]. An endometrioma is form as these cells replicate and create a discrete mass [2]. The first case was reported in 1860 and the true prevalence is unknown [3]. Its estimated prevalence in women of childbearing age is $10 \%$, related to infertility in $35-50 \%$ [4]. Endometriosis causes a sustained reduction of ovarian reserve through both physical mechanisms and inflammatory reactions [5].

Ectopic endometrial tissue is generally located in the pelvis, but can also be found in the lungs, intestine, ureters, brain, and abdominal wall [6]. Abdominal wall endometriosis
(AWE) is any ectopic endometrium superficial to the peritoneum, the definition includes lesions that may or may not be related to previous surgical procedures. Endometriosis is usually located close to a surgical scar. Although in most cases occurs in patients with previous cesarean section and hysterectomy. It has also been observed in postoperative, conventional or laparoscopic appendectomy and inguinal hernia incisions, and it has been described in patients without any previous intervention [7]. The prevalence related to these procedures is estimated between 17 to $57 \%$ [8].

The mean time between surgery and presentation of symptoms is 2.1 to 3.6 years, and recurrence after 
resection is $4.3 \%$ [9]. The most common symptom is a palpable mass that occurs in $96 \%$ of patients, followed by abdominal pain in $86 \%$ and cyclical pain associated with menstruation in $57 \%$ [5]. Data from different studies affirm that the global prevalence is as low as $0.03 \%-1.08 \%$ depending on the sample and place of study [3].

There must be a great clinical suspicion after physical examination. Common findings at evaluation are a tender, immobile, palpable mass. Which in most cases is associated with the presence of a previous surgical scar, and the overlying skin may be discolored. In the largest series published, the average size of the AWE was $2.7 \mathrm{~cm}$. [8] The differential diagnosis that should be considered at time of initial evaluation includes hernias, lipoma, abscess, desmoid tumors, and malignancy [14].

Multiple imaging options exist and may aid in the diagnosis as well as surgical planning. While ultrasound should be considered first to confirm clinical suspicion, both computed tomography (CT) scans and magnetic resonance imaging (MRI) can help in surgical planning [2].

The treatment of choice in the specific case of abdominal wall endometriosis is excision of the lesion with negative margins. This surgical method provides the best opportunity for diagnosis and definitive treatment $[6,14]$.

No prospective trials have been performed to evaluate prevention of abdominal wall endometriomas. In cesarean deliveries, this would include irrigation of the surgical site has been proposed as a method to prevent AWE and prompt removal of surgical sponges from the field that were used to clean the uterus $[9,18]$.

\section{Case Report}

A 37- year-old female patient consulted for presenting a sensation of mass in the left lateral abdominal wall, associated with abdominal pain in the left hemiabdomen. In the physical examination, a mass located in the lower region between the left rectus abdominis muscle and the semilunar line was found on palpation, which was painful, this mass was $5 \mathrm{~cm}$ from a previous Pfannenstiel-type surgical wound. The patient reports that the symptoms appeared 24 months after the last cesarean section, but the symptoms worsened in the last 15 days reaching a disabling due to the pain, and she required an emergency visit to our institution. The patient's personal history included disabling dysmenorrhea from the age of 13, which improved with pregnancies; in addition, three caesarean sections 10, 6 and 3 years ago respectively; Within the surgical descriptions of caesarean sections, no foci of endometriosis were found.

To make the diagnosis, we based on a previous consultation 2 months after the onset of symptoms, in an institution outside our city. Where an abdominal ultrasound was performed, which revealed a $31 \times 21 \times 25 \mathrm{~mm}$ vascularized mass in the abdominal wall with heterogeneous characteristics (Figure 1, 2).

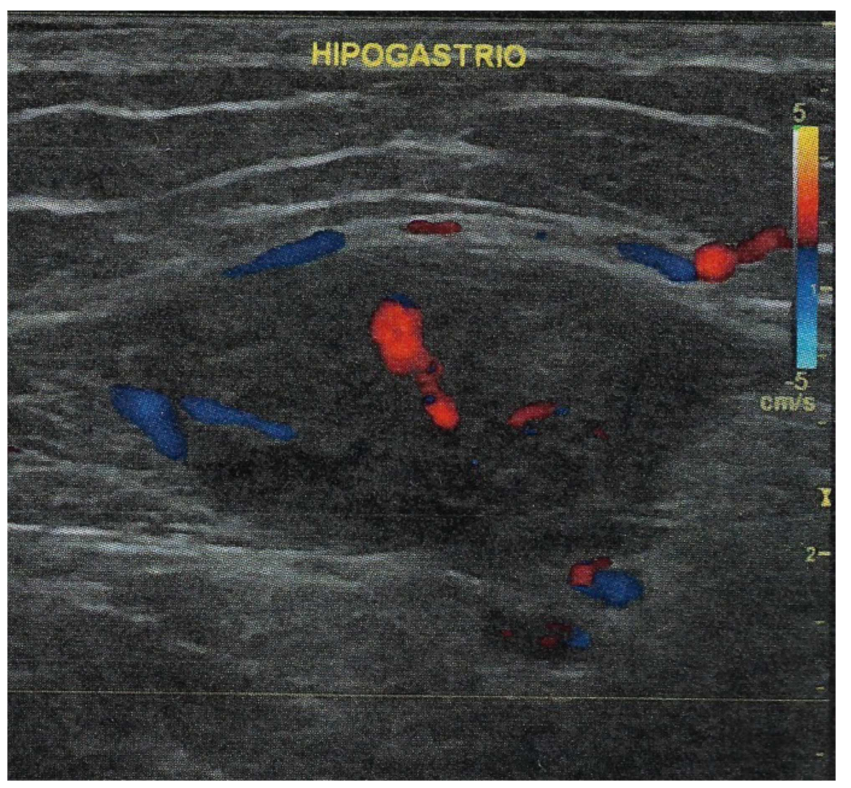

Figure 1. Ultrasonography of the anterior abdominal wall left paramedian region. A vascularized mass with a volume of $4.7 \mathrm{cc}$ is evidenced. Transverse diameter of $3.37 \mathrm{~cm}$ and anteroposterior of $2.22 \mathrm{~cm}$.

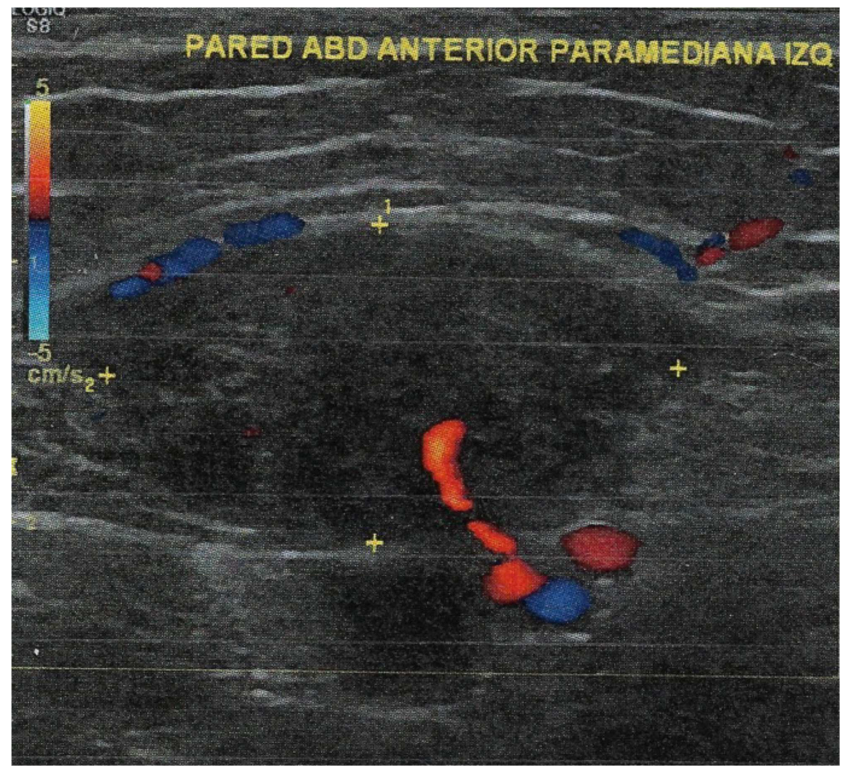

Figure 2. Hypogastric ultrasonography. Another vision of the mass previously described.

The patient, upon admission to the emergency department in the gynecology service of our institution, presented with acute abdominal pain, with intensity $10 / 10$ on the visual analog pain scale (VAS), with characteristics of an acute abdomen, for which we decided to carry out a surgical procedure immediately.

During the intervention, a mass of around $4 \times 5 \mathrm{~cm}$ was found that compromised the left rectus abdominis muscle and infiltrated the anterior wall of the abdominal cavity. The muscle segment was resected and the posterior myorrhaphy was performed, samples were taken for study. The histopathological analysis revealed findings of striated muscle with endometrial glands with inflammatory infiltrate and foci of hemorrhage, in addition to well-vascularized adipose tissue 
with a nest of endometrial tissue (Figure 3).

Months after surgery, the patient did not show recurrence of symptoms.

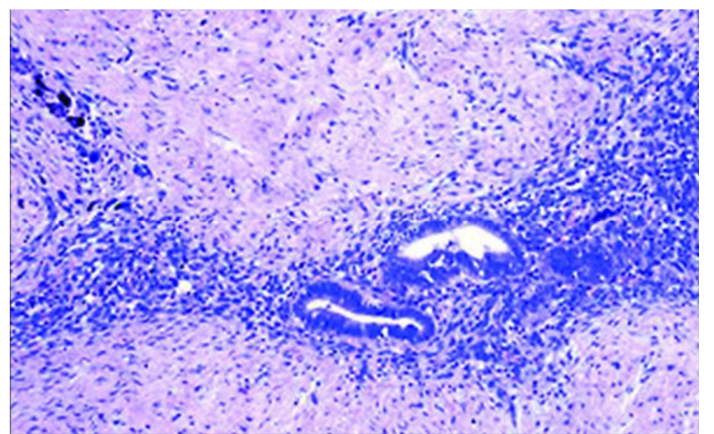

Figure 3. Histopathology. Endometriotic glands are observed embedded in muscle tissue corresponding to the rectus abdominis. In addition to a marked inflammatory infiltrate.

\section{Discussion}

Endometriosis is the presence of endometrial glands and stroma outside the uterine cavity $[10,11]$. Theoretically it can affect any organ of the body [12]. One of the less common locations is the abdominal wall, whose prevalence is as low as $0.03-1.08 \%[3,13]$. The first case in the literature was reported in 1860 [3]. It affects women, mainly of reproductive age, more frequently between 29.1 to 33.8 years [14, 15]; being less prevalent after menopause, it can manifest itself in cases of hormone replacement therapy [16, 17]. It is normally related to previous gynecological and obstetric surgical procedures, presenting as a mass close to the scar generated, generally painful with physical effort or in relation to the menstrual period, and may increase in size cyclically. The average time of onset between surgery and symptoms varies from 10 months to 5 years. [14, 18, 19]

Among the localization patterns in the abdominal wall, the rectus abdominis muscle is the most affected with $46.6 \%$, followed by the external oblique of the abdomen in $33.3 \%$, pre-aponeurotic lesions in $13.3 \%$ and the least affected, the transverse abdominal muscle with $6.8 \%$. [20]

Its diagnosis continues to be a problem for health professionals, due to its role as a "imitator", sharing characteristics with clinical pictures of more frequent pathologies such as hernias, hematomas, lymphadenopathy, lymphomas, lipomas, abscesses, subcutaneous cysts, neuromas, granulomas, soft tissue sarcomas, dermoid tumors, metastatic cancer among others. [14, 20-22]

Khan et al. [23] conducted a retrospective case-control study $(\mathrm{n}=102)$ in order to recognize the risk factors associated with abdominal endometriosis. They found that patients with a diagnosis of abdominal endometriosis had greater parity $(>2$ deliveries, $\mathrm{p}$ value $<0.001)$, higher BMI $(>29.2 \mathrm{~kg} / \mathrm{m} 2 \mathrm{p}$ value 0.02$)$, greater chronic pain $(>30$ months $p$ value 0.029$)$ cyclical ( $p$-value 0.005) and association with previous surgeries (adjusted OR 61.9). However, the sample studied was not significant.

In relation to the pathophysiology, there are different theories related to the origin of endometriosis at the level of the abdominal wall. One of them is related to the transport of endometrial tissue after a surgical procedure, where decidual cells with pluripotential capacity in an estrogen environment can generate an endometrioma. The mechanisms include inflammation and metalloproteinases activation due to local growth factors, estrogen stimulation through estrogen receptors and potential epigenetic changes. Non-uterine endometrial cells require metalloproteinases for tissue remodeling and interaction. These enzymes are activated by factors, such as TGF $\beta$ [24]. The theory of retrograde menstruation states that the ectopic endometrium is "displaced" through the fallopian tubes to later implant in any site of the peritoneal cavity and replicate, during the menstrual period. This theory is supported when menstrual blood is found in peritoneal fluid in up to $90 \%$ of healthy women. Recent studies suggest the transformation of progenitor stem cells from the bone marrow into endometrial tissue and coelomic metaplasia that involves the conversion of normal peritoneal tissue into ectopic endometrial tissue. [18, 25] On the other hand, the benign metastasis theory holds that ectopic endometrial implants are the result of lymphatic or hematogenous spread of endometrial cells. This would explain the role of the lymphatic system in the genesis of ovarian endometriosis by spreading endometrial cells through the lymphatic flow that goes from the uterine body to the ovaries. This theory would explain the distant and histologically documented endometriotic lesions such as in the lung, brain and bones $[14,18,26]$. It is important to highlight that, the histological findings of the endometrial tissue are composed of a single layer of cylindrical epithelium supported by a fibrous stroma wall. The superficial epithelium then invaginates into the stroma to form glandular structures [27, 28]. However, none of the theories fully explains the pathogenesis of this disease.

Cardinal symptoms in this pathological entity are reported as a mass in the abdominal wall in up to $96 \%$ of cases followed by pain in $87 \%$, cyclical pain is reported with a percentage of $57 \%$, these clinical findings concur with pelvic endometriosis in $13 \%$ of cases $[14,18]$. Other signs and symptoms usually include hemorrhages from lesions that are superficial, and non-localized pain in hemiabdomen lower, dysmenorrhea was not shown to be a good predictor of abdominal endometriosis (p 0.004). [14, 20, 22, 23]

The presumptive diagnosis of this pathology is achieved through paraclinical imaging studies. Ultrasound is used in $93.3 \%$ of cases; the TAC and NMR in $16.6 \%$. There are no pathognomonic imaging findings of endometriosis. Images may vary based on menstrual cycle. On ultrasound, patterns of stromal remnants, endometrial glands and hemorrhages can be found, such as hypoechoic, heterogeneous images with increased vascularization; on MRI, hypointense, isointense and hyperintense homogeneous images with heterogeneous focal areas of high or low intensity can be found suggestive of hemorrhage or fibrosis. Conclusive diagnosis is made by image-guided fine needle aspiration biopsy or excisional biopsy for subsequent histopathological study. [17, 18, 20, 21, 29] 
The treatment that best suits the specific case of abdominal wall endometriosis is excision of the lesion with negative margins. This surgical method provides the best opportunity for diagnosis and definitive treatment. In more than $95 \%$ the surgical method provides a definitive cure, with only $4.3 \%$ recurrence [14-16, 30, 31]. It is important that during the procedure the resection margins are widened, since if even a minimal endometriotic lesion persists, the recurrence increases exponentially; Therefore, it is recommended to resect at least $1 \mathrm{~cm}$ of healthy perilesional tissue as well as remove the intact complete piece to avoid dissemination [32]. There are multiple techniques for the repair of the defect of the abdominal wall. One of them is the mini abdominoplasty plus mesh placement, which has been reported to be effective in treatment with low recurrence rates. [33]

Hormonal treatment with contraceptives, such as danazol, or others based on progestogens without the use of the surgical method, has not shown efficacy in the resolution of symptoms. At the same time, no benefits have been seen in the postoperative period, but it is recommended to use it only in patients with a history of pelvic endometriosis, if it occurs after surgery. [14, 17, 28, 21, 30, 34]

Among new treatment options, the use of $95 \%$ ethanol injection guided by ultrasound to the endometriosis focus is proposed, arguing that the surgical method increases the risk of defects in the abdominal wall (hernias, eventrations, etc.). This method has had positive results, absent the focus of endometriosis after treatment. This is recommended only in abdominal wall endometriosis, since intraperitoneally it can generate chemical peritonitis; despite, this could be an alternative option to the treatment of abdominal wall endometriosis. Although there are not studies with a representative statistical sample, it can be taken into consideration. [27, 35, 36].

Endometriosis of any site has an associated malignancy risk of $1 \%$. Eighty percent of malignancy cases are related to endometriosis located at the ovary, and $20 \%$ of these cases are related to extra-gonadal locations (including the abdominal wall). Malignant tumors with poor prognosis are clear cell adenocarcinoma followed by endometrioid adenocarcinoma; The treatment for endometriosis-associated malignant transformation in an abdominal surgical scar is extensive surgery and adjuvant chemotherapy and/or radiotherapy. [36]

\section{Conclusions}

Abdominal Endometriosis is a rare entity in medical practice. A high index of suspicion should be considered in the case of a woman presenting with disabling abdominal pain located in the abdominal wall, with a history of previous gynecological surgical procedures. This pathology can be confused with many other surgical entities; For this reason, resorting to paraclinical studies can be essential in the diagnostic certainty. The availability of imaging studies and the precision of the fine needle biopsy are strategies that bring us closer to the definitive diagnosis. After surgical treatment, clinical follow-up is necessary due to the risk of recurrence.

\section{Acknowledgements}

Special gratitude to the Departmental Hospital of Nariño for the excellent care and commitment to medical academic training in our country.

\section{References}

[1] Photiou, L., Tan, C.-G., \& Taylor, K. O. (2019). Abdominal Wall Endometriosis in an Abdominoplasty Patient. Aesthetic Plastic Surgery. 43: 980-981. doi: 10.1007/s00266-019-01402-9.

[2] Rindos NB, Mansuria S. (2017) Diagnosis and Management of Abdominal Wall Endometriosis: A Systematic Review and Clinical Recommendations. Obstet Gynecol Surv.; 72 (2): 116-122. doi: 10.1097/OGX.0000000000000399. PMID: 28218772 .

[3] Saliba, C., Jaafoury, H., El Hajj, M., Nicolas, G., \& Haidar Ahmad, H. (2019). Abdominal Wall Endometriosis: A Case $\begin{array}{llll}\text { Report. Cureus Feb; } 11 \text { (2), e4061. } & \text {. }\end{array}$ doi.org/10.7759/cureus.4061.

[4] Lee D, Kim SK, Lee JR, Jee BC. (2020) Management of endometriosis-related infertility: Considerations and treatment options. Clin Exp Reprod Med.; 47 (1): 1-11. doi: 10.5653/cerm.2019.02971. Epub 2020 Feb 24. PMID: 32088944; PMCID: PMC7127898.

[5] Djakovic I, Vukovic A, Bolanca I, Soljacic Vranes H, Kuna K (2017) Abdominal wall endometriosis eleven years after cesarean section: case report. Acta Clin Croat 56 (1): 162-165. https://doi.org/10.20471/acc.2017.56.01.22.

[6] Costa J, Faria E et al. (2020). Abdominal wall endometriosis: experience of the General Surgery Service of the Antônio Pedro University Hospital of the Universidade Federal Fluminense. Rev. Col. Bras. Cir., Rio de Janeiro, v. 47, e20202544. https://doi.org/10.1590/0100-6991e-20202544.

[7] Ortega R., Serrano F., Prieto S. et al. (2012) Abdominal wall endometriosis. Prog Obstet Ginecol. 55 (8): 367-372. DOI: 10.1016/j.pog.2011.09.011.

[8] Parasar, P., Ozcan, P., \& Terry, K. L. (2017). Endometriosis: Epidemiology, Diagnosis and Clinical Management. Current obstetrics and gynecology reports, 6 (1), 34-41. https://doi.org/10.1007/s13669-017-0187-1.

[9] Anand M, Deshmukh SD. (2011) Massive abdominal wall endometriosis masquerading as desmoid tumour. J Cutan Aesthet Surg.; 4: 141-143.

[10] Burney, R., \& Giudice, L. (2012). Pathogenesis and Pathophysiology of Endometriosis. Fertility and Sterility, 98 (3), 265-275. http://doi.org/10.1007/s10955-011-0269-9.Quantifying.

[11] Cöl, C., \& Yilmaz, EE (2014). Cesarean scar endometrioma: Case series. World Journal of Clinical Cases, 2 (5), 133-6. http://doi.org/10.12998/wjcc.v2.i5.133.

[12] Medina, B., M itsui, N., Centurión, O., Recalde, A., Ayala, N., Ojeda, H., \& Bogado, L. (2009). Case Report Endometriosis of the abdominal wall. Presentation of a case. EFACIM, 42 (2), $67-72$. 
[13] Tatli, F., Gozeneli, O., Uyanikoglu, H., Uzunkoy, A., Yalcın, H. C., Ozgonul, A., Guldur, ME (2017). The clinical characteristics and surgical approach of abdominal wall endometriosis: A case series of 14 women. Bosnian Journal of Basic Medical Sciences, http://doi.org/10.17305/bjbms.2018.2659.

[14] Horton, JD, DeZee, KJ, Ahnfeldt, EP, \& Wagner, M. (2008). Abdominal wall endometriosis: a surgeon's perspective and review of 445 cases. American Journal of Surgery, 196 (2), 207-212. http://doi.org/10.1016/j.amjsurg.2007.07.035.

[15] Singh, KK, Lessells, AM, Adam, DJ, Jordan, C., Miles, WF, Macintyre, IM, \& Greig, JD (1995). Presentation of endometriosis to general surgeons: a 10 -year experience. The British Journal of Surgery, 82 (10), 1349-51. Retrieved fromhttp://www.ncbi.nlm.nih.gov/pubmed/7489161.

[16] Lopez -Soto, A., Sanchez -Zapata, MI, Martinez-Cendan, JP, Ortiz Reina, S., Bernal Mañas, CM, \& Remezal So lano, M. (2018). Cutaneous endometriosis: Presentation of 33 cases and literature review. European Journal of Obstetrics Gynecology and Reproductive Biology, 221, 58-63. http://doi.org/10.1016/j.ejogrb.2017.11.024.

[17] Nissotakis, C., Zouros, E., Revelos, K., \& Sakorafas, GH (2010). Abdominal wall endometrioma: A case report and review of the literature. AORN Journal, 91 (6), 730- 742. http://doi.org/10.1016/j.aorn.2010.01.014.

[18] Bozkurt, M., Said, A., \& Bozkurt, D. (2014). Intramuscular abdominal wall endometriosis treated by ultrasound-guided ethanol injection. Clinical Medicine and Research, 12 (3-4), 160-165. http://doi.org/10.3121/cmr.2013.1183.

[19] Kang, J., Baek, J.-H., Lee, W.-S., Cho, TH, Lee, JN, Lee, WK, \& Chung, M. (2013). Clinical manifestations of abdominal wall endometriosis: a single center experience. Archives of Gynecology and Obstetrics, 287 (2), 301-305. http://doi.org/10.1007/s00404-012-2565-2.

[20] Khlifi, A., Kouira, M., Anis, M., Sonia, Z., Ines, L., Habib, S., Hedi, K. (2012). Endométrios e pariétale sur cicatrice de Césarienne: À propos de 3 cas. Imagerie of LaFemme, 22 (3), 156-161. http://doi.org/10.1016/j.femme.2012.06.003.

[21] Grigore, M., Socolov, D., Pavaleanu, I., Scripcariu, I., Grigore, AM, \& Micu, R. (2017). Abdominal wall endometriosis: An upd ate in clinical, imagistic features, and management options. Medical Ultrasonography, 19 (4), 430-437. http://doi.org/10.11152/mu-1248.

[22] Malutan, AM, Simon, I., Ciortea, R., Mocan- Hognogi, RF, Dudea, M., \& Mihu, D. (2017).Surgical Scar Endometiosis: a Series of 14 Patients and Brief Review of Literature. Clujul Medical, 0 (0), 411-415. http://doi.org/10.15386/cjmed-743.

[23] Khan, Z., Zanfagnin, V., El- Nashar, SA, Famuyide, AO, Daftary, GS, \& Hopkins, MR (2017). Risk Factors, Clinical Presentation, and Outcomes for Abdominal Wall Endometriosis. Journal of Minimally Invasive Gynecology, 24 (3), 478-484. http: // doi. org / 10.1016 / j. jmig.2017.01.005.

[24] Carsote M., Terzea D., Valea A., Gheorghisan A. (2020) Abdominal Wall Endometriosis (A narrative review)
International Journal of Medical Sciences, 17 (4) 536-542 doi: 10.7150/ijms.38679.

[25] Petrosellini, C., Abdalla, S., \& Oke, T. (2018). The many guises of endometriosis: Giant abdominal wall endometriosis masquerading as an incisional hernia. International Journal of Fertility and Sterility, 11 (4), 321-325. http://doi.org/10.22074/ijfs.2018.5126.

[26] Eljuga, Damir \& Klarić, Petar \& Bolanča, Ivan \& Grbavac, Ivan \& Kuna, Krunoslav. (2012). Abdominal wall endometriosis: Case report. Acta clinica Croatica. 51. 261-3.

[27] Bergeron C. Histologie et physiologie de l'endomètre normal. EMC (Elsevier Masson SAS, Paris), Gynécologie, 31-L-10, 2006.

[28] Huber M., Grosel J., Showen C. (2019) Recognizing abdominal wall endometriosis. American Academy of Pshysician $\begin{array}{llll}\text { Assistants, } & 32 & \text { (7). } & \text { DOI: }\end{array}$ 10.1097/01.JAA.0000558237.67863.aa.

[29] Meyer R. Adenomatous proliferation of the serosa in an abdominal scar. Z Ge burtsh Gynak 1903; 49: 32-41.

[30] Gupta, P., \& Gupta, S. (2015). Scar Endometriosis: a Case Report with Literature Review. Acta Med Iran, 53 (12), $793-$ 795.

[31] Vellido-Cotelo, R., Muñoz-González, JL, Oliver-Pérez, MR, de la Hera-Lázaro, C., Almansa-González, C., Pérez- Sagaseta, C., \& Jiménez-López, JS (2015). Endometriosis node in Gynaecologic scars: A study of 17 patients and the diagnostic considerations in clinical experience in tertiary care center. BMC Women's Health, 15 (1). http://doi.org/10.1186/s12905-015-0170-9.

[32] Blanco RG., Parithivel VS, Shah AK, Gumbs MA, Schein M, Gerst PH. Abdominal wall endometriomas. Am J Surg 2003; 185: 596-598.

[33] Zhao, R., Wang, X.-J., Song, K.-X., Zhu, L., \& Li, B. (2012). Mini abdominoplasty combined with mesh used for abdominal wall endometriosis. Chinese Medical Journal, 125 (9), 1614-7. Retrieved http://www.ncbi.nlm.nih.gov/pubmed/228008311955.

[34] Singh, M., Sivanesan, K., Ghani, R., \& Granger, K. (2009). Caesarean scar endometriosis. Archives of Gynecology and Obstetrics, 279 (2), 217-219. http://doi.org/10.1007/s00404-008-0672-x.

[35] Chang, M.-Y., Hsieh, C.-L., Shiau, C.-S., Hsieh, T.-T., Chiang, R.-D., \& Chan, C.-H. (2013). Ultrasound-Guided Aspiration and Ethanol Sclerotherapy (EST) for Treatment of Cyst Recurrence in Patients after Previous Endometriosis Surgery: Analysis of Influencing Factors Using a Decision Tree Journal of Minimally Invasive Gynecology, 20 (5), 595-603. http://doi.org/10.1016/j.jmig.2013.03.004.

[36] García-Tejedor, A., Castellarnau, M., Ponce, J., Fernández, M., \& Burdio, F. (2015). Ethanol sclerotherapy of ovarian endometrioma: a safe and effective minimal invasive procedure. Preliminary results. European Journal of Obstetrics \& Gynecology and Reproductive Biology, 187, 25-29. http://doi.org/10.1016/j.ejogrb.2015.02.004. 